\title{
Incidence and risk factors of gestational diabetes in Karnataka Institute of Medical Sciences, Hubli
}

\author{
Vinaya G, Surekha S. M.*, Shivaganga Chiniwal
}

Department of Obstetrics and Gynecology, Koppal Institute of Medical sciences, Koppal, Karanataka, India

Received: 02 December 2020

Accepted: 05 January 2021

\section{*Correspondence:}

Dr. Surekha S.M.,

E-mail: drsiri.sm@gmail.com

Copyright: (c) the author(s), publisher and licensee Medip Academy. This is an open-access article distributed under the terms of the Creative Commons Attribution Non-Commercial License, which permits unrestricted non-commercial use, distribution, and reproduction in any medium, provided the original work is properly cited.

\begin{abstract}
Background: Gestational diabetes is essentially the development of diabetes in pregnancy with a return to normal glucose tolerance after delivery. Objective of the study was to know incidence and risk factors of gestational diabetes in Karnataka Institute of Medical Sciences, Hubli.

Methods: This prospective study conducted in KIMS Hubli, for a period of one year from October 2009 to November 2010, in all pregnant women attending OPD of OBG Department. The number of cases included in the study was 200. Results: Incidence of GDM was found to be $3.5 \%$ in the 200 patients studied. Patients were in the age group 18-36 yrs. There was increasing in the incidence after 25 yrs. There is gradual increase in prevalence of GCT positive case with increasing age. $60 \%$ of the patients had risk factors. Risk factors of importance were positive family history $40 \%, \mathrm{BMI}>27$ was $37.5 \%$.

Conclusions: Gestational diabetes mellitus can be present in patients without risk factors. Hence the need for universal screening. Glucose challenge test with $75 \mathrm{~g}$ glucose at 2 hours is highly sensitive in detecting GDM.
\end{abstract}

Keywords: Age group, Gestational diabetes mellitus, Incidence, Risk water

\section{INTRODUCTION}

Virtually all new cases of diabetes in pregnancy are a transient form of type II diabetes. A small proportion of cases of de novo diabetes are found to persist after pregnancy. Most of these are type H DM. However rarely Type I DM will arise during pregnancy simply as a matter of coincidence. ${ }^{1}$

Pregnancy is considered to be a diabetogenic state characterized by exaggerated rate and amount of insulin release, associated with decreased sensitivity to insulin at cellular levels. Hormones like estrogen, progesterone, human placental lactogen, cortisol and growth hormone are anti insulinogenic. These hormones increase in mid pregnancy period and cause abnormal glucose tolerance in some women rendering them prone for gestational diabetes. ${ }^{2}$ Women with a history of GDM are at increased risk of future diabetes, predominately type 2 diabetes, as are their children. The importance of GDM is that two generations are at risk of developing diabetes in the future .Besides any abnormal glucose tolerance during pregnancy also has adverse fetal outcome. ${ }^{3}$

Increasing maternal carbohydrate intolerance in pregnant without GDM is associated with a graded increase in adverse maternal and fetal outcomes. ${ }^{4}$ It is important to identify a pregnant woman with gestational diabetes mellitus because GDM is associated with significant metabolic alterations, increased perinatal mortality and morbidity, maternal morbidity and exaggerated long tenn morbidity among the mothers and their offspring. ${ }^{5}$

Universal screening of all pregnant women for GDM has been endorsed by both the American Diabetes Association Position Statement and by the First, Second, third international workshop conferences on GDM. ${ }^{6-8}$ American College of Obstetricians and Gynecologists 
(ACOG) have emphasized on selective screening. ${ }^{9}$ The Fourth International Workshop conference in Gestational diabetes also endorsed on selective screening. ${ }^{10}$

Compared with selective screening, universal screening for GDM detects more cases and improves maternal and offspring prognosis. ${ }^{11}$ In the Indian context, screening is essential in all pregnant women as the Indian women have an eleven fold increased risk of developing glucose intolerance during pregnancy compared to Caucasian women. ${ }^{12}$ Another area of concern is that among ethnic groups in South Asian countries, the Indian women have the highest frequency of GDM. ${ }^{13}$

The prevalence of gestational diabetes in India in 1980 was $2 \%$ only, in 1990 it was $7 \%$ and in 2000 it was $16.55 \%$. This diabetic explosion is mainly due to obesity pandemic which is attributed to sedentary life style and diet changes. Indians have an 11 fold risk of developing diabetes mellitus during pregnancy. ${ }^{14}$

In the ensuring half decade there have been plenty of research papers and GDM has been proved as a disease entity. But there is a lot of controversy regarding many aspects of GDM. Important being type of screening, whether universal or selective, which screening tests and diagnostic test to follow, about ideal cut off levels, whether to treat or not, how to treat best so on and so forth. Unfortunately there is no universally accepted gold standard for diagnosis of GDM and the commonly utilized methods and threshold criteria for diagnosis of GDM in themselves give different results. The pandemic of diabetes and its related complications continues unabated in spite of strides which have been made in the understanding of diabetes and the availability of new therapeutic interventions. If one is to put in place initiations which are preventive in nature, the women with a history of GDM as well as offspring exposed to maternal diabetes in utero should be a major concern.

That too Indian data on GDM is scant and does not give the actual picture. India falls under high risk group and with the advent of western life style, incidence of type II DM is raising steeply. The number of women with GDM is also raising, hence the need for this study. Hence an attempt is made to evaluate to know Incidence and risk factors of gestational diabetes in Karnataka Institute of Medical Sciences, Hubli. The need for universal screening and outcome of pregnancy in those with borderline values, mode of treatment.

\section{METHODS}

This was a prospective study conducted in KIMS Hubli, for a period of one year from October 2009 to November 2010 , in all pregnant women attending OPD of OBG Department. The number of cases included in the study was 200. Pregnant women attending antenatal OPD with gestational age between 24-28 weeks were included in the study and pregnant women diagnosed with diabetes prior to pregnancy i.e. pre-gestational diabetes were excluded from the study.

200 pregnant women attending the OPD underwent detailed clinical examination as per proforma, irrespective of presence or absence of risk factors. 75 grams of glucose was dissolved in $300 \mathrm{ml}$ of water and the patient was asked to drink it over a five minute period, irrespective of time of the day and her last meal. After 2 hours of ingestion of glucose, venous blood was drawn. The plasma glucose was estimated by glucose oxidation and peroxidation (GOD-POD) method by EcoPak glucose kit.

Glucose oxidase (GOD) converts glucose to ghiconie acid. Hydrogen peroxide formed in this reaction, in the presence of peroxidase (POD), oxidatively couples with 4-aminoantipyrine and phenol to produce red quinoneimine dye. This dye has absorbance maximum at $505 \mathrm{~nm}(500-550 \mathrm{~nm})$. The intensity of the color complex is directly proportional to the concentration of glucose in the specimen.

If plasma glucose value was $>140 \mathrm{mg} / \mathrm{d} 1$, the screening was considered as positive. Patients with GCT value of $200 \mathrm{mg} / \mathrm{dl}$ or more were directly diagnosed as GDM without the need for OGTT. The GCT positive patients underwent diagnostic OGTT, by $100 \mathrm{gm}$ of glucose. Three days prior to OGTT test, patients were asked to take normal unrestricted diet. After overnight fasting of 8-14 hours, a fasting blood sample was drawn, following which $100 \mathrm{gm}$ of glucose dissolved in $300-400 \mathrm{~m} 1$ of water was given orally. Thereafter venous glucose plasma levels were assessed hourly for three hours. Patients were diagnosed as GDM by Carpentar and Coustan values. Those diagnosed as GDM were admitted, evaluated, treated and followed till delivery and also after puerperium. Maternal and perinatal outcomes were studied.

\section{Statistical analysis}

Data was entered in Microsoft excel, graphs were drawn using Microsoft and Microsoft excel. Data was analysed using SPSS software version. Statistical tests like Fischer exact test was used.

\section{RESULTS}

A prospective study was carried on pregnant women with 24 - 28 weeks gestation over a period of one year October 2009 September 2010. Data collected is presented here.

Acceptability: Among the 200 patients there were no incidence of adverse effects of nausea and vomiting. All the patients accepted the test readily (Table 1).

Characteristics of positive screen are as follows: There is gradual increase in prevalence of GCT positive case with 
increasing age. $\mathrm{P}<0.05$ was statistically significant in the age $>30$ years was seen Table 2 .

Table 1: Distribution of cases according to GCT and OGIT.

\begin{tabular}{|lllll|}
\hline \multirow{4}{*}{ GCT } & \multicolumn{5}{c}{ OGTT } & & \\
\cline { 2 - 5 } & Positive & Negative & Total \\
\cline { 2 - 5 } & Positive & $7(\mathrm{a})$ & $3(\mathrm{~b})$ & 10 \\
\hline & Negative & $0(\mathrm{c})$ & $190(\mathrm{~d})$ & 190 \\
\hline & Total & 7 & 193 & 200 \\
\hline
\end{tabular}

Sensitivity $=\mathrm{a} / \mathrm{a}+\mathrm{c} \times 100 ; 7 / 74 * 100=100 \%$

Specificity $=b / b+d \times 100 ; 190 / 193 \times 100=98.44 \%$

Positive predictive value $=\mathrm{a} /(\mathrm{a}+\mathrm{b}) \times 100 ;=(7 / 10) * 100$ $=70 \%$

Negative predictive value $=\mathrm{d} /(\mathrm{c}+\mathrm{d}) \times 100 ;=(190 / 190) *$ $100=100 \%$

Table 2: Age distribution of GCT positive case.

\begin{tabular}{|lllll|}
\hline Age & No. of cases & $\%$ & GCT+ve & $\%$ \\
\hline $\mathbf{2 0}$ & 27 & 13.5 & 0 & 0 \\
\hline $\mathbf{2 1}$ to $\mathbf{2 4}$ & 92 & 46 & 3 & 3.3 \\
\hline $\mathbf{2 5}$ to 29 & 62 & 31 & 4 & 6.5 \\
\hline $\mathbf{3 0}$ to 34 & 13 & 6.5 & 3 & 23.1 \\
\hline$>\mathbf{3 5}$ & 6 & 3 & 0 & 0 \\
\hline
\end{tabular}

Table 3: BMI distribution of GCT positive cases.

\begin{tabular}{|lllll|}
\hline BMO & $\begin{array}{l}\text { No. of } \\
\text { patients }\end{array}$ & $\%$ & GCT+ve & $\%$ \\
\hline$<20$ & 28 & 14 & 1 & 3.57 \\
\hline $\mathbf{2 1}$ to 24 & 138 & 70 & 3 & 2.17 \\
\hline $\mathbf{2 5}$ to 29 & 32 & 15 & 5 & 15.63 \\
\hline $\mathbf{3 0}$ to 34 & 1 & 0.5 & 0 & 0.00 \\
\hline$>\mathbf{3 5}$ & 1 & 0.5 & 1 & 100.00 \\
\hline
\end{tabular}

Table 4: Distribution of GCT positive cases according to risk factor.

\begin{tabular}{|lllll|}
\hline Risk factors & Total & $\begin{array}{l}\text { GCT } \\
\text { +ve }\end{array}$ & $\%$ & $\begin{array}{l}\text { Fischer } \\
\text { exact } \\
\text { test P value }\end{array}$ \\
\hline Age $>$ 30 years & 19 & 3 & 15.7 & $<0.05$ \\
\hline Family H/o & 10 & 4 & 40 & $<0.05$ \\
\hline Previous loss & 9 & 1 & 11.11 & $>0.05$ \\
\hline PCOS & 1 & - & - & NA \\
\hline Twin & 2 & - & - & NA \\
\hline BMI $>$ 27 & 8 & 4 & 50 & $<0.05$ \\
\hline
\end{tabular}

Incidence of GDM was found to be $3.5 \%$ in the 200 patients studied. Patients were in the age group 18-36 years. There was increasing in the incidence after 25 years Table $3.60 \%$ of the patients had risk factors. Risk factors of importance were positive family history $40 \%$, BMI > 27 was $37.5 \%$ Table 4,5 .
Table 5: Percentage of GCT positive cases with and without risk factors.

\begin{tabular}{|lll|}
\hline Risk factors & No of cases & Percentage \\
\hline With risk factors & 6 & 60 \\
\hline Without risk factors & 4 & 40 \\
\hline Total & 10 & 100 \\
\hline
\end{tabular}

GCT was positive in 10 cases, of which $70 \%$ were OGTT positive. Fischer exact p-value $<0.05$ is statistically significant in risk factors like age $>30$ years, family $\mathrm{h} / \mathrm{o}$ and BMI $>27$. GCT was positive in $40 \%$ of cases without the risk factors. Therefore universal screening is needed.

\section{DISCUSSION}

Gestational diabetes mellitus is a Carbohydrate intolerance of variable severity with the onset or first recognition during the present pregnancy". GDM is associated with important prenatal and long term health risks and many of the risks increases in relation to the severity of maternal hyperglycemia.

Green et al showed that incidence of GDM was significantly greater for Chinese $(7.3 \%)$ and Hispanic $(4.2 \%)$ women than for blacks. ${ }^{15}$ Ferrara et al also showed the incidence at $7.5 \%$ in Asians, $5.6 \%$ in Hispanics, 4\%, African American. ${ }^{16}$ Engelgau et al reported that whilst GDM complicates about 5\% of all pregnancies, but the rate of occurrence can range up to $14 \%$ depending on the population subgroup.

The incidence of diabetes in the world at large and in India in particular is on the raise. Indian population is ethnically prone to high prevalence of type II DM. In such population, incidence of GDM is also high. ${ }^{17}$ Incidence of GDM ranges from $0.2 \%$ - $12 \%$ depending on the population studied. In Indian context our women have 11 fold increase in rate of developing GDM. ADA noticed that $7 \%$ of all pregnancies are complicated by GDM and in our study the incidence is $3.5 \%$.

The specificity of the test was $100 \%$ in Anjalakshi et al and also in our study, so were the sensitivity test with 75 grams glucose. ${ }^{12}$ The positive predictive value was high compared to Carpenter and Coustan's study indicating that screening with 75 grams glucose is a more sensitive test in detecting GDM.

Sheshiah et al report from their study that using $75 \mathrm{~g}$ glucose at $2 \mathrm{~h}$ plasma glucose $>140 \mathrm{mg} / \mathrm{d} 1$ as one step procedure is simple and economical, particularly for the countries ethnically prone to high prevalence of GDM. ${ }^{18}$

Anjalakshi et al in their study of 800 pregnant women diagnosed as GDM by 75g GCT glucose, irrespective of the last meal timings, found no statistically significant difference $(\mathrm{p}>0.005)$ between the plasma glucose levels of GCT and WHO OTT performed in the GDM and the normal glucose tolerance pregnant women. ${ }^{19}$ 
Esakoff et al also examined if the screening criteria should be modified depending on the ethnicity of the subject being tested. ${ }^{20}$ Bonomo et al recommended the threshold of $140 \mathrm{mg} / \mathrm{d} 1$ as a cut off point for screening GDM, as the lower threshold values are associated with high false positive rate, increasing the economic burden. Taking $140 \mathrm{mg} / \mathrm{d} 1$ as a cutoff point, only $14 \%$ require OGTT whereas, $23 \%$ require OGTT with $130 \mathrm{mg} / \mathrm{d} 1$ as a cutoff point. ${ }^{21}$ If the prevalence of GDM is high in a particular population group, a cutoff point of $130 \mathrm{mg} / \mathrm{d} 1$ is a reasonable threshold level. And a higher false positive rate is also acceptable.

Established risk factors for GDM are advanced maternal age, obesity and family history of diabetes. Sheshialin et al noted increase in the prevalence of GDM in their study and attributed it to increased BMI, as high maternal weight is associated with a substantially higher risk of GDM. $^{22}$

Jang et al found that the GDM women were older, had higher pre pregnancy weight, higher BMI, higher parities and higher frequencies of known diabetes in the family. ${ }^{23}$ Of all the independent risk factors for GDM, BMI emerged as a modifiable risk factor. GDM women have high risk of developing diabetes in the future. They are the ideal group to be targeted for lifestyle modification or pharmacologic intervention in order to delay or postpone the onset of overt diabetes. Hence an important public health priority in the prevention of diabetes is to address maternal health both during antenatal and post-partum period.

Solomon et al study showed advance maternal age, family history of diabetes mellitus, non-white ethnicity, higher BMI, weight gain in early adulthood and cigarette smoking predicts increased GDM risk and this observations facilitate the identification of women at particular risk for GDM and suggests potential strategies for reducing the risk even before a women becomes pregnant such as avoiding substantial weight gain and smoking. ${ }^{24}$

Maternal age is an established risk factor for gestational diabetes mellitus (GDM), but there is no consensus on the age above which there is significantly increased risk of GDM. In the literature, the lowest cut off is $>25$ years, as recommended by the American Diabetes Association. Though the incidence in different age groups varies, in all studies, there is an increase in incidence of GDM as the age advances.

Terence et al finding indicates that the risk of GDM becomes significantly and progressively increased from 25 years onwards. ${ }^{25}$ This supports the American Diabetes Association recommendation on the use of age $>25$ years as the cutoff for screening and the observation that maternal age $>25$ years is the factor most predictive of GDM. In clinical practice, maternal age of $>25$ years should be adopted instead of $>35$ years or 40 years as a risk factor for the development of GDM.

\section{CONCLUSION}

Gestational Diabetes Mellitus can be present in patients without risk factors. Hence the need for universal screening. Glucose challenge test with $75 \mathrm{~g}$ glucose at 2 hours is highly sensitive in detecting GDM. For universal screening, single OGTT with $75 \mathrm{~g}$ glucose load and diagnosing women with $2 \mathrm{hr}$ PPG $>140 \mathrm{mg} / \mathrm{d} 1$ as GDM. This method recommended by WHO serves both as a one step screening and diagnostic procedure and is easy to perform besides being economical. Timely intervention with diet, insulin therapy, patient education and team approach for the treatment improves the outcome of pregnancy.

\section{ACKNOWLEDGMENTS}

Authors would like to express their profound gratitude to all the participants for their co-operation and for their help in the study.

\section{Funding: No funding sources}

Conflict of interest: None declared

Ethical approval: The study was approved by the Institutional Ethics Committee

\section{REFERENCES}

1. Hyde J, Treloar E. Robert Fox. Progress in OBG. $16^{\text {th }}$ edition. 52-72.

2. Diana R, Danilenko DMD, Winter V, Roger L, Nelson MD, Paul L, et al. Universal versus selective gestational diabetes screening : application of 1997 American Diabetes Association recommendations. Am J Obstet Gynecol. 1999;181:798-80.

3. Dorniorst A, Rossi M. Risk and prevention of type 2 diabetes in women with Gestational diabetes. Diabetes Care. 1998;21(2):43-9.

4. Sermer M, Naylor CD, Farine D. The Toronto Tri Hospital Gestational diabetes Project- a preliminary review. Diabetes Care. 1998;21(2):33-42.

5. First International Workshop. Conference on gestational diabetes mellitus summary and recommendations. Diabetes Care. 1980;3:499-501.

6. American Diabetes Association. Summary and recommendations of second International workshop conference on gestational diabetes mellitus. Diabetes care. 1985;34(2):123-6.

7. Metzger BE. The organising committee: summary and recommendations of third international workshop - conference on gestational diabetes mellitus. Diabetes. 1991;40 (2):197-201.

8. Coustan DR. ACOG Practice Bulletin number 30 gestational diabetes. Am J Obstet Gynecol. 2001;5:525-37.

9. Metzer BE, Coustan DR. Summary and recommendations of the fourth international 
workshop conference on gestational diabetes mellitus. Diabetes care. 1998;21:161-7.

10. Miller HC. The effect of prediabetic state on survival of the fetus and the birth weight of the new born infant. N Engl J Med. 1945;233:376-8.

11. Casson E. Screening and insulin sensitivity in gestational diabetes. Abstract volume of the 40th Annual Meeting of the EASD. 2004:350.

12. Dornhorst A, Paterson CM, Nicholls JS. High prevalence of gestational diabetes in women from ethnic minority groups. Diabet Med. 1992;9:820-5.

13. Beischer NA, Oats JN, Henry OA. Incidence and severity of gestational diabetes mellitus according to country of birth in women living in Australia. Diabetes. 1991;40(2):35-8.

14. Singh A. Screening of gestational diabetes mellituswhy? when? and bow? Obs Gynec. 2009;14(6):233.

15. Kjos SI, Henry 0A, Montoro M, Buchanan TA, Mestman requiring diabetes in pregnancy a randomized trial of induction of labor andexpectant management. Am J Obstet Gvnecol. 1993;169:611-5.

16. Ferrara A, Hedderson MM, Quesenberry CP, SelbyJ. Prevalence of GDM detected by NDDG or the CandC plasma glucose thresholds. Diabetes Care. 2002;25:1625-30.

17. Diabetes and pregnancy. American College of Obstetrician and Gynecologists Technical. 1994.

18. Sheskiab V, Balaji V, Balaji MS. One step for screening and diagnosis of gestational diabetes mellitus. J Obstet Gynecol India. 2005;55;525-9.

19. Anjalakshi K, Balaji H, Madhuri J. A single procedure to diagnose gestational diabetes mellitus. Ada Diabetol. 2009;46:51-4.
20. Esakoff T, Cheag Y, Caughey A. Screening for GDM: different cutoffs for different ethnicities? Am J Obstet Gyneco1. 2005; 193:1040.

21. Bonomo M, Gandini ML, Mastropasqua A. The definition of screening methods for gestational diabetes study group of the lombardy section of the Italian society of diabetology. Am J Obstet Gynecol. 1998;179:179-85.

22. Seshiah V, Balaji V, Madhuri S, Balaj A, Paneerselvam T, Arthi M. Prevalence of gestational diabetes mellitus in South India (Tamil Nadu) a community based study. Assoc Physicians India. 2008;56:329-33.

23. Jang HC, Cho NH, Jung KB, Oh KS, Dooley SL, Metzger BE. Screening for gestational diabetes mellitus in Korea. Int $\mathbf{J}$ Gynecol Obstet. 1995;51:115-22.

24. Solomon CG, Willett WC, Carey VJ, Rich JE, Hunter DJ, Coldittz GA. A prospective study of pregravid determinants of gestational diabetes mellitus. JAMA. 1997;278:1078-83.

25. Terence T. Lao MD, Lai FH, Ben CP. Maternal age and prevalence of gestational diabetes mellitus. Diabetes Care. 2006;29:948-9.

Cite this article as: Vinaya G, Surekha SM, Chiniwal S. Incidence and risk factors of gestational diabetes in Karnataka Institute of Medical Sciences, Hubli. Int J Reprod Contracept Obstet Gynecol 2021;10:609-13. 